\title{
Dietary sugars analysis: quantification of fructooligossacharides during fermentation by HPLC-RI method
}

\section{Daniela M. Correia ${ }^{1}$, Luís G. Dias ${ }^{2}$, Ana C. A. Veloso ${ }^{1,3}$, Teresa Dias ${ }^{2}$, Isabel Rocha ${ }^{1}$, Lígia R. Rodrigues ${ }^{1}$ and António M. Peres ${ }^{4}$ *}

${ }^{1}$ Centre of Biological Engineering (CEB), University of Minho, Braga, Portugal

${ }^{2}$ Centro de Investigação de Montanha (CIMO), Escola Superior Agrária, Instituto Politécnico de Bragança, Bragança, Portugal

${ }^{3}$ Departamento de Engenharia Química e Biológica (DEQB), Instituto Superior de Engenharia de Coimbra, Instituto Politécnico de Coimbra, Coimbra, Portugal

${ }^{4}$ Laboratory of Separation and Reaction Engineering (LSRE) - Associate Laboratory LSRE/LCM, Escola Superior Agrária, Instituto Politécnico de Bragança,

Bragança, Portugal

\section{Edited by:}

Jun Lu, Auckland Unversity of

Technology, New Zealand

Reviewed by:

Victor Costa Castro-Alves, University of São Paulo, Brazil

Reza Nemati, Auckland University of

Technology, New Zealand

${ }^{*}$ Correspondence:

António M. Peres, LSRE - Escola

Superior Agrária, Instituto Politécnico

de Bragança, Campus Santa

Apolónia, Apartado 1172, 5301-855

Bragança, Portugal

e-mail:peres@ipb.pt
In this work, a simple chromatographic method is proposed and in-house validated for the quantification of total and individual fructooligossacharides (e.g., 1-kestose, nystose, and $1^{F}$-fructofuranosylnystose). It was shown that a high-performance liquid chromatography with refractive index detector could be used to monitor the dynamic of fructooligossacharides production via sucrose fermentation using Aspergillus aculeatus. This analytical technique may be easily implemented at laboratorial or industrial scale for fructooligossacharides mass-production monitoring allowing also controlling the main substrate (sucrose) and the secondary by-products (glucose and fructose). The proposed chromatographic method had a satisfactory intra- and inter-day variability (in general, with a relative standard deviation lower than $5 \%$ ), high sensitivity for each sugar (usually, with a relative error lower than $5 \%$ ), and low detection (lower than $0.06 \pm 0.04 \mathrm{~g} / \mathrm{L}$ ) and quantification (lower than $0.2 \pm 0.1 \mathrm{~g} / \mathrm{L}$ ) limits. The correct quantification of fructooligossacharides in fermentative media may allow a more precise nutritional formulation of new functional foods, since it is reported that different fructooligossacharides exhibit different biological activities and effects.

Keywords: dietary sugars, fructooligossacharides, HPLC-RI method, yield fermentation process, in-house validation

\section{INTRODUCTION}

Fructooligosaccharides (FOS) are dietary sugars quite used as food ingredients and are usually incorporated as dietary fibers in many food products. FOS, are calorie-free and non-carcinogenic sweeteners enabling the improvement of the gastrointestinal physiology and immune functions (1-3). However, despite the current positive evidence of FOS's effect against infections (4-6) some studies report that, under some specific conditions, FOS may cause the growth of pathogenic bacteria $(7,8)$. For instance, FOS reduce the colonization of Salmonella enteritidis, but concomitantly increase the translocation of this invasive pathogen $(9,10)$. On other hand, Silva et al. (11) observed that FOS reduced Klebsiella sp. translocation. The different behaviors observed can be a result of genetic diversity between pathogenic bacteria. Recently, Schouler et al. (12) described the presence of a gene cluster involved in the metabolism of short-chain FOS in a pathogenic Escherichia coli BEN2908. So, FOS's characterization and quantification is needed and required namely for food-labeling purposes since, for instance, the use of absolute values of a specific nutrient may allow a better understanding by the consumer about possible health effects (13, 14). Different structurally oligossacharides have been referred as FOS, namely, 1-kestose, nystose, and $1^{\mathrm{F}}$-fructofuranosylnystose. Accordingly, FOS are considered prebiotics with several health benefits, playing a key role in individual health and being effective against chronic inflammatory diseases $(15,16)$. Based on its current definition (United Nations' Food and Agriculture Organization - FAO), a prebiotic is a non-viable food component that confers a health benefit to the host associated with modulation of the microbiota $(17,18)$. These compounds have a huge economic relevance in the food industry and a great health impact, being increasingly important in food and nutrition sciences $(2,3,19)$. FOS are usually present in plants or fruits $(15,19-21)$ although in low concentrations and their individual relative proportion vary considerable from plant to plant which, from an industrial point of view, may not be economically viable to obtain them by extraction. Alternatively, FOS may be produced, either by fermentation from raw materials rich in sucrose, or by the action of enzymes with transfructosylation activity that can be derived from microorganisms (16, 22-26). Therefore, it is highly relevant to have fast, cost-effective, and accurate analytical techniques that enable the simultaneous quantification of the existent mono- and disaccharides in a fermentative medium (namely glucose, fructose, and sucrose), as well as the most common FOS (namely 1-kestose, nystose, and $1^{\mathrm{F}}$-fructofuranosylnystose), which may differ in both molecular structure and weight depending on their source. Furthermore, the biological activity and its physiological effect may depend not only on the total FOS concentration but also on the specific molecular structure, although the analytical distinction 
and identification of a particular oligosaccharide is still difficult (27). Zdunczyk et al. (28) reported that, when compared with a kestose-rich preparation, the administration of a nystose-rich diet increased the concentration of volatile fatty acids in rats. Also, Pejin et al. (29) observed that nystose exhibit a higher antihydroxyl radical activity than 1-kestose, showing that the nystose can be a more active natural product. Nevertheless, FOS quantification requires the use of a systematic analytical approach, being chromatographic techniques the most widespread tools for sugar analysis $(2,19)$, although the majority of them are technically demanding, time-consuming, and expensive. In the last two decades, several chromatographic techniques have been proposed for FOS identification and/or quantification in plants or fruits, namely thin-layer chromatography, high-performance liquid chromatography (HPLC), and gas chromatography coupled or not to mass-spectrometry $(13,19,22,27,30-33)$. Massspectrometry (MS) based-techniques are usually applied due to the low content of FOS found in plants and fruits. Nevertheless, most of these techniques present technical and analytical constrains being high-performance anion-exchange chromatography (HPAEC) with pulsed amperometric detector (PAD) and liquid chromatography MS the most used for FOS analysis (19). Borromei et al. $(34,35)$ applied HPAEC-PAD or HPAEC coupled with pulse electrochemical detector (PED) to quantify FOS in milks. Also, Feinberg et al. (36) proposed and validated a HPAEC-PAD method to determine complex polysaccharides, including FOS, in foods. Recently, Blanch et al. $(15,21)$ quantified FOS (e.g., 1kestose, neokestose, nystose, nystose b, and kestopentaose) in food matrices using HPAEC-PAD. On the other hand, HPLC with PAD or refractive index (RI) detector have also been used to identify and quantify glucose, fructose, sucrose, and FOS derivatives kestose, nystose, and 1-fructofuranosylnystose in fermentative media (16, $23,25,26,37$ ), revealing to be a suitable routine technique considering their high levels present in fermentation samples. Other techniques have also been proposed and successfully applied for FOS detection, identification, and/or quantification, namely nuclear magnetic resonance, fluorophore-assisted carbohydrate electrophoresis, matrix-assisted desorption/ionization time-offlight MS, or even using HPLC coupled with electrospray ionization tandem MS $(19,38,39)$. Even so, these last techniques are not commonly used since they are technically demanding (19) and far beyond the economic capacity of the majority of FOS producers.

In this study, a HPLC-RI method, which uses a $\mathrm{NH}_{2}$ stationary phase column, is proposed and in-house validated, for the simultaneous quantification of individual FOS (1-kestose, nystose, and $1^{\mathrm{F}}$-fructofuranosylnystose), mono- and disaccharides (glucose, fructose, and sucrose). The main objective was to demonstrate that a simple, fast, and cost-effective chromatographic approach could be used to accurately follow the dynamic of FOS production via sucrose fermentation using Aspergillus aculeatus, which could be easily implemented for screening studies at laboratorial scale or even used by industry for FOS mass-production monitoring.

\section{MATERIALS AND METHODS \\ REAGENTS AND STANDARDS}

All chemicals were of analytical grade and used as purchased. The FOS standards, 1-kestose, nystose, and $1^{\mathrm{F}}$-fructofuranosylnystose (purchased from Fluka or Wako Pure Chemical Industries, Ltd., Japan) had a minimum purity of 98,98 , and $80 \%$, respectively. Before use, all aqueous standard solutions were filtered using nylon membranes with a porosity of $0.2 \mu \mathrm{m}$ (Puradisc $25 \mathrm{NYL}$ with a diameter of $25 \mathrm{~mm}$, from Whatman) and were stored at $-20^{\circ} \mathrm{C}$ until analysis. All solvents were of analytical grade without any further purification. Acetonitrile of HPLC grade (Lab-Scan) had a minimum purity of $99.8 \%$ (supplied by Merck). Deionized water was obtained using a water purification system (TGI pure water system). Before use, all solvents were filtered using nylon membranes with a porosity of $0.2 \mu \mathrm{m}$ (Whatman) and degassed during at least $15 \mathrm{~min}$.

\section{HPLC ANALYSIS AND EQUIPMENT}

A Knauer HPLC system equipped with a Knauer SmartLine 1000 pump, an automatic solvent degassing system (Knauer Manager 5000), a RI detector (RI Knauer SmartLine 2300) and a manual injector with a $20 \mu \mathrm{L}$ loop was used. The chromatographic separation was achieved using a Knauer Eurospher 100-5 $\mathrm{NH}_{2}$ Vertex $25 \mathrm{~mm} \times 4.6 \mathrm{~mm}$ column (with a security guard cartridge), at $35.0 \pm 0.1^{\circ} \mathrm{C}$, placed inside an oven (Grace, model 7971R). Isocratic elution was achieved using a mixture of acetonitrile and $0.04 \%$ ammonium hydroxide in water $(70: 30 \mathrm{v} / \mathrm{v})$ at a flow rate of $1.25 \mathrm{ml} / \mathrm{min}$. Each sample was analyzed in triplicate.

\section{HPLC-RI METHOD IN-HOUSE VALIDATION}

The HPLC method used to detect and quantify mono-, disaccharides, and FOS was evaluated for linearity, detection, and quantification limits, accuracy, and precision (assays performed for repeatability and intermediate precision).

\section{Intra- and inter-day HPLC injection variability}

An external standard calibration methodology was applied to identify and quantify the sugars under analysis (fructose, glucose, sucrose, 1-kestose, nystose, and $1^{\mathrm{F}}$-fructofuranosylnystose). Linearity was evaluated using nine sugar standard solutions with concentrations ranging from 0.2 to $25.5 \mathrm{~g} / \mathrm{L}$ (Table 1). They were prepared individually by consecutive dilutions from a stock solution containing a known concentration of each compound, which was assessed by weight. Injection intra-day repeatability was studied by evaluating the relative standard deviation percentage (\%RSD) of the retention times (27 injections for each sugar) and the area values ( 3 injections for each sugar and concentration level) from the results recorded for the triplicate analysis of each standard solution in the same day. Injection inter-day repeatability was evaluated based on the \%RSD values obtained from the retention times (36 values for each sugar) and area values (4 values for each sugar and concentration level) recorded for each of the nine standard solutions analyzed once in four consecutive days.

\section{Linearity, limits of detection and of quantification}

The results were plotted for evaluating the linear relationship between the peak areas of each sugar and their concentrations. Calibration curves for each sugar were established based on the data recorded during triplicate analysis carried out in the same day (intra-day variability), as well as from the chromatographic profiles recorded during four consecutive days (inter-day variability). 
Table 1 | Standard solutions concentrations used for establishing the calibration curves

Standard solution

\begin{tabular}{|c|c|c|c|c|c|c|}
\hline & & & & & & \\
\hline & Fructose & Glucose & Sucrose & 1-Kestose & Nystose & ${ }_{1} F_{\text {-Fructofuranosylnystose }}$ \\
\hline $\mathrm{P} 1$ & 0.253 & 0.252 & 0.252 & 0.250 & 0.252 & 0.250 \\
\hline $\mathrm{P} 2$ & 0.506 & 0.503 & 0.504 & 0.500 & 0.504 & 0.500 \\
\hline P4 & 1.01 & 1.01 & 1.01 & 1.00 & 1.01 & 1.00 \\
\hline P5 & 2.53 & 2.52 & 2.52 & 2.50 & 2.52 & 2.50 \\
\hline P8 & 20.2 & 20.1 & 20.1 & 20.0 & 20.1 & 20.0 \\
\hline P9 & 25.3 & 25.2 & 25.2 & 25.0 & 25.2 & 25.0 \\
\hline
\end{tabular}

One-way analysis of variance (ANOVA) was used to assess the statistical significance of each linear regression model being the quality of the fitted models evaluated by their correlation coefficient values (R-Pearson). The statistical significances of the slope and of the intercept values were evaluated by a $t$-test. The regression data for consecutive days were subjected to a likelihood ratio test of equality (covariance analysis) to infer about interday variability of the calibration curves enabling the decision if it is necessary to establish a new calibration curve whenever a new FOS quantification is required. Statistic analyses were performed using the SPSS 17 Standard Version software (SPSS INC.) at a 5\% significance level. Detection (LOD) and quantification (LOQ) limits were calculated using the parameters of the calibration curves, being defined as 3.3 and 10 times the value of the regression error divided by the slope, respectively $(40,41)$.

\section{HPLC instrumental precision, accuracy, and recovery assays}

Instrumental precision was evaluated to verify the repeatability of the chromatographic analysis. The instrumental system precision was studied using three standard quality control solutions (QCS) with known concentrations $(0.7,11$, and $20 \mathrm{~g} / \mathrm{L}$ for each sugar) of the six sugars under study, which corresponded to low, middle, and high concentrations according to the dynamic range of the calibration curves. These levels were also evaluated since it was expected that, during the fermentation with A. aculeatus, FOS levels could vary from 0 to $200 \mathrm{~g} / \mathrm{L}$ (37), which could be easily quantified after proper dilutions. Each solution was injected, under the working conditions, three times on the same day to evaluate the repeatability of the instrumental system (i.e., intra-day variation, considering only within day variations). The accuracy of the HPLC method was evaluated by comparing the real concentration of each sugar in each QCS and the calculated concentrations using the calibration curves previously established. The instrumental precision and accuracy were assessed by calculating the $\%$ RSD and the relative error percentage (\%RE). Further, with the purpose of evaluating the recovery performance of the method, a fermentation sample was collected at $84 \mathrm{~h}$ of fermentation (to ensure that fructose, glucose, sucrose, and the three individual FOS were present in the sample at appreciate levels). After filtration, the sample was diluted $(1: 8, \mathrm{v} / \mathrm{v})$ and split into four aliquots of $200 \mu \mathrm{L}$, one unfortified and the other three fortified with all the analytes at three different concentrations $(25,50$, and $100 \mu \mathrm{L}$ of a $25 \mathrm{~g} / \mathrm{L}$ stock solution). This procedure was done in triplicate.

\section{FOS FERMENTATION SAMPLES}

The HPLC-RI method developed was applied to monitor the FOS production via sucrose fermentation by $A$. aculeatus. The fermentation inoculum $(25 \mathrm{~mL})$ was prepared at a spore concentration of $1 \times 10^{6}$ spores $/ \mathrm{mL}$. The fermentation medium $(500 \mathrm{~mL}$; with $200 \mathrm{~g} / \mathrm{L}$ of sucrose, $20 \mathrm{~g} / \mathrm{L}$ of $\mathrm{NaNO}_{3}, 0.5 \mathrm{~g} / \mathrm{L}$ of $\mathrm{KCl}, 0.01 \mathrm{~g} / \mathrm{L}$ of $\mathrm{FeSO}_{4} .7 \mathrm{H}_{2} \mathrm{O}, 0.35 \mathrm{~g} / \mathrm{L}$ of $\mathrm{K}_{2} \mathrm{SO}_{4}$, and $7.89 \mathrm{~g} / \mathrm{L}$ of $\mathrm{KH}_{2} \mathrm{PO}_{4}, \mathrm{pH} 5.0$ ) was prepared in a $2 \mathrm{~L}$ flask with baffles. After sterilization (15 min at $121^{\circ} \mathrm{C}$ ) the fermentation was carried out in an incubator with orbital agitation (OVAN, model OPAC/ACOP) at $27^{\circ} \mathrm{C}$ and 150 rpm during 7 days. Twice a day a sample $(5 \mathrm{~mL})$ was collected and filtrated through a $0.2 \mu \mathrm{m}$ Nylon filter (Whatman) and kept at $-20^{\circ} \mathrm{C}$ until chromatographic analysis. Whenever necessary, samples were diluted before analysis. Three fermentation replicas were carried out.

\section{RESULTS AND DISCUSSION}

In this work, it was performed the in-house validation of an HPLCRI method for the quantification of the main sugars (monosaccharides - glucose and fructose; disaccharides - sucrose; and FOS - 1-kestose, nystose, and $1^{\mathrm{F}}$-fructofuranosylnystose) that may be present in the FOS production by sucrose fermentation using A. aculeatus. This fungus was used since it was previously reported as one of the most promising FOS-producing fungi (42) and it has been widely described as a fructusyltransferase producer suggesting that it could be used in a single step fermentation for FOS production $(3,37)$.

A typical chromatographic profile of those sugars is shown in Figure 1 that corresponds to the standard solution P4 (Table 1) containing an average concentration of each sugar of $1 \mathrm{~g} / \mathrm{L}$. In this figure, it is also shown a typical chromatogram of a fermentation sample. From Figure 1, it is clear that a good separation of the different sugars peaks can be obtained, especially regarding FOS, in a 25 min single chromatographic run, even for fermentation samples.

\section{INTRA- AND INTER-DAY HPLC INJECTION VARIABILITY}

The results obtained for intra-day and inter-day variability assays of the chromatographic injections, evaluated using the nine 

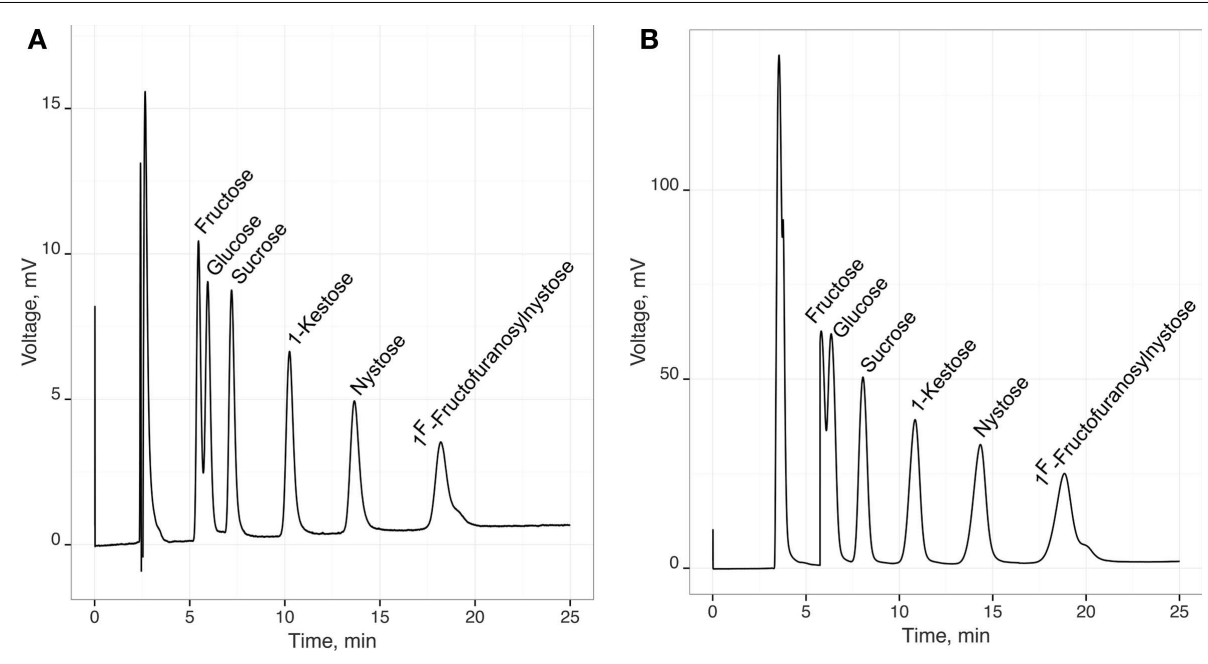

FIGURE 1 |Typical chromatogram recorded for a standard solution (A) and a fermentation sample (B) containing fructose, glucose, sucrose, 1-kestose, nystose, and $1^{\mathrm{F}}$-fructofuranosylnystose

standard solutions, concerning retention times, and peak areas, are given in Tables 2 and 3, respectively.

Since the intra-day and inter-day \%RSD values were usually lower than $5 \%$, it is possible to conclude that the within and between days chromatographic injection variability is globally satisfactory for all the sugars analyzed (40). These results are in accordance with those reported by Borromei et al. (35) for intraand inter-day variation of glucose, fructose, sucrose, and 1-kestose retention times in samples, analyzed using HPAEC coupled with pulse electrochemical detection (PED).

\section{LINEARITY, LIMITS OF DETECTION AND OF QUANTIFICATION}

The linearity of the HPLC-RI method, for the calculation of glucose, fructose, sucrose, 1-kestose, nystose, and $1^{\mathrm{F}}$ fructofuranosylnystose, was evaluated through the calibration curves obtained by linear regression $(R \geq 0.9991)$, considering the peak area for each sugar, in arbitrary units (Figure 1), vs. the concentration of each sugar $(\mathrm{g} / \mathrm{L})$. The calibration correlation coefficients are of the same magnitude as those obtained by Borromei et al. (34) using a HPAEC coupled with PAD for similar concentration dynamic ranges.

All the linear calibration models were statistically significant, as well as all the slope values $(P \leq 0.001)$. Repeatability and intermediate precision of the calibration curves were evaluated by establishing the calibration curves based on the chromatographic runs recorded in the same day and on four consecutive days (Table 4). In both cases, two linear dynamic ranges were defined (from 0.25 to $2.5 \mathrm{~g} / \mathrm{L}$; and 2.5 and $25 \mathrm{~g} / \mathrm{L}$ ) allowing the determination of LOD and LOQ values (Tables 4 and 5) lower than the lowest concentration included in the experimental range $(0.25$ or $2.5 \mathrm{~g} / \mathrm{L}$, respectively), which were calculated from the calibration parameters $(40,41)$. The establishment of two linear dynamic ranges was required since a slight curvature (as can be inferred by comparing the different slope values obtained - Tables 4 and 5) was observed within the overall concentration range evaluated. Depending on the FOS concentrations found in each fermentation sample, and
Table 2 | Intra- and inter-day variabilities for sugars retention times (27 injections).

Compound

Retention time (minutes)

\begin{tabular}{lccccc}
\cline { 5 - 6 } & \multicolumn{2}{c}{ Intra-day assays } & & \multicolumn{2}{c}{ Inter-day assays } \\
\cline { 2 - 3 } & $\overline{\boldsymbol{t}}_{\boldsymbol{R}} \pm \boldsymbol{s}$ & \%RSD & & $\overline{\boldsymbol{t}}_{\boldsymbol{R}} \pm \boldsymbol{s}$ & \%RSD \\
\hline Fructose & $5.57 \pm 0.02$ & 0.34 & & $5.6 \pm 0.1$ & 2.16 \\
Glucose & $6.10 \pm 0.02$ & 0.30 & & $6.1 \pm 0.2$ & 2.55 \\
Sucrose & $7.48 \pm 0.03$ & 0.34 & & $7.4 \pm 0.3$ & 3.57 \\
1-Kestose & $10.84 \pm 0.04$ & 0.40 & & $10.7 \pm 0.6$ & 5.18 \\
Nystose & $14.66 \pm 0.07$ & 0.45 & & $14.4 \pm 0.9$ & 6.49 \\
1F-Fructofuranosylnystose & $19.8 \pm 0.1$ & 0.52 & & $19 \pm 1$ & 7.74 \\
& & & & &
\end{tabular}

$\bar{t}_{R} \pm s:$ average retention time \pm standard deviation; $\% R S D$, relative standard deviation percentage.

to avoid large dilutions, the most adequate calibration curve was used. Furthermore, a covariance analysis, applied to the calibration curves for each sugar (data not shown), indicated that the linear regressions obtained in four consecutive days were not statistically different $(P \geq 0.100)$, thus meaning that the same calibration curve could be used during at least 1 week for quantification purposes. Also, LOD and LOQ values obtained for intra- and inter-day analysis are, usually, of the some magnitude, showing a satisfactory precision. Moreover, from the analysis of the results shown in Tables $\mathbf{4}$ and 5, it is evident that the calculated LOD (varying from 30 to $60 \mu \mathrm{g} / \mathrm{mL}$ ) and LOQ (varying from 100 to $200 \mu \mathrm{g} / \mathrm{mL}$ ) values were always lower than the lowest standard concentration tested in each dynamic interval of the calibration curves, indicating a satisfactory sensitivity for each sugar standard. Overall, LOD and LOQ values are much higher than those reported [e.g., (1)] for MS based-techniques (at nanograms per milliliter level). On the other hand LOD and LOQ values of the proposed HPLC-RI method are in the same range but slightly higher than those 
Table 3 | Intra- and inter-day repeatabilities of sugars peak areas (one injection in four consecutive days).

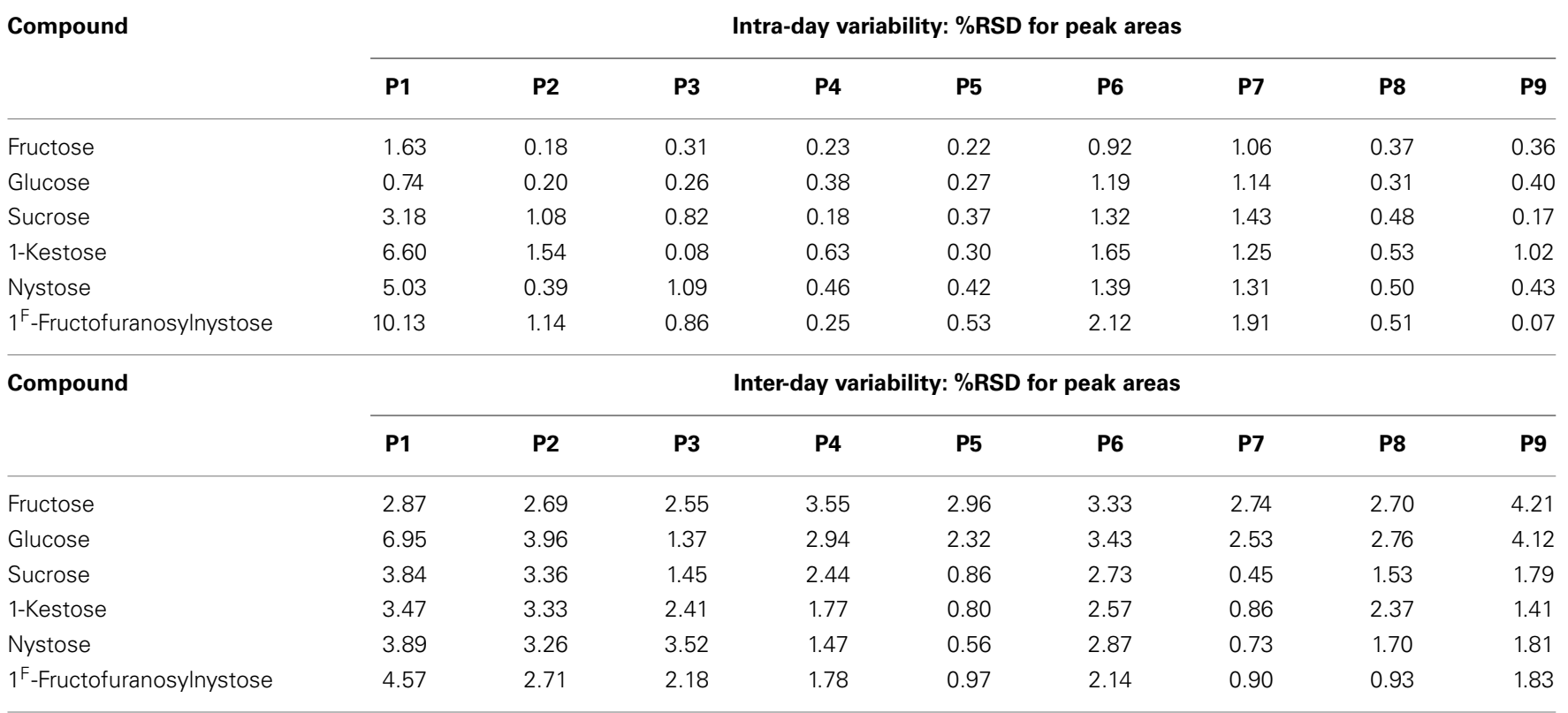

$\% R S D$, relative standard deviation percentage.

Table 4 | Calibration curves for the dynamic range covering concentrations between 0.25 and $2.5 \mathrm{~g} / \mathrm{L}$.

\begin{tabular}{|c|c|c|c|c|c|c|c|}
\hline & & \multicolumn{6}{|c|}{ Compound $(\bar{x} \pm s)$} \\
\hline & & Fructose & Glucose & Sucrose & 1-Kestose & Nystose & $1^{F}$-Fructofuranosylnystose \\
\hline \multirow[t]{4}{*}{ Repeatability (three injections) } & Slope (L/g) & $128.4 \pm 0.4$ & $120.3 \pm 0.4$ & $171.9 \pm 0.7$ & $171.4 \pm 0.7$ & $155.8 \pm 0.5$ & $112.2 \pm 0.2$ \\
\hline & R-Pearson & $>0.9999$ & $>0.9999$ & $>0.9998$ & $>0.9999$ & $>0.9998$ & $>0.9997$ \\
\hline & $\operatorname{LOD}(g / L)$ & $0.03 \pm 0.01$ & $0.03 \pm 0.01$ & $0.04 \pm 0.01$ & $0.030 \pm 0.004$ & $0.04 \pm 0.01$ & $0.05 \pm 0.03$ \\
\hline & LOO (g/L) & $0.11 \pm 0.02$ & $0.11 \pm 0.02$ & $0.12 \pm 0.03$ & $0.10 \pm 0.01$ & $0.14 \pm 0.02$ & $0.2 \pm 0.1$ \\
\hline \multirow[t]{4}{*}{ Intermediate precision (4 days) } & Slope (L/g) & $128 \pm 4$ & $120 \pm 4$ & $171 \pm 2$ & $170 \pm 2$ & $154 \pm 2$ & $110 \pm 1$ \\
\hline & R-Pearson & $>0.9998$ & $>0.9997$ & $>0.9996$ & $>0.9996$ & $>0.9991$ & $>0.9997$ \\
\hline & LOD (g/L) & $0.04 \pm 0.01$ & $0.04 \pm 0.02$ & $0.04 \pm 0.03$ & $0.04 \pm 0.03$ & $0.06 \pm 0.04$ & $0.04 \pm 0.03$ \\
\hline & LOO (g/L) & $0.12 \pm 0.05$ & $0.13 \pm 0.06$ & $0.1 \pm 0.1$ & $0.13 \pm 0.09$ & $0.2 \pm 0.1$ & $0.1 \pm 0.1$ \\
\hline
\end{tabular}

$L O D$, detection limit; $L O Q$, quantification limit; $(\bar{x} \pm s)$, average \pm standard deviation.

Table 5 | Calibration curves for the dynamic range covering concentrations between 2.5 and $25 \mathrm{~g} / \mathrm{L}$.

\begin{tabular}{|c|c|c|c|c|c|c|c|}
\hline & & \multicolumn{6}{|c|}{ Compound $(\bar{x} \pm s)$} \\
\hline & & Fructose & Glucose & Sucrose & 1-Kestose & Nystose & $1^{F}$-Fructofuranosylnystose \\
\hline \multirow[t]{4}{*}{ Repeatability (three injections) } & Slope (L/g) & $132.3 \pm 0.4$ & $123.7 \pm 0.4$ & $176.0 \pm 0.1$ & $178 \pm 2$ & $159.6 \pm 0.4$ & $112.9 \pm 0.1$ \\
\hline & R-Pearson & $>0.9997$ & $>0.9997$ & $>0.9997$ & $>0.9996$ & $>0.9996$ & $>0.9994$ \\
\hline & $\operatorname{LOD}(\mathrm{g} / \mathrm{L})$ & $0.65 \pm 0.07$ & $0.67 \pm 0.08$ & $0.6 \pm 0.2$ & $0.7 \pm 0.2$ & $0.8 \pm 0.2$ & $0.8 \pm 0.2$ \\
\hline & LOQ (g/L) & $2.2 \pm 0.2$ & $2.2 \pm 0.3$ & $1.9 \pm 0.7$ & $2.4 \pm 0.6$ & $2.6 \pm 0.6$ & $2.8 \pm 0.8$ \\
\hline \multirow[t]{4}{*}{ Intermediate precision ( 4 days) } & Slope (L/g) & $132 \pm 5$ & $124 \pm 5$ & $175 \pm 3$ & $177 \pm 3$ & $159 \pm 2$ & $112 \pm 2$ \\
\hline & R-Pearson & $>0.9995$ & $>0.9995$ & $>0.9993$ & $>0.9994$ & $>0.9993$ & $>0.9996$ \\
\hline & LOD (g/L) & $0.7 \pm 0.3$ & $0.7 \pm 0.3$ & $0.7 \pm 0.4$ & $0.8 \pm 0.2$ & $0.8 \pm 0.4$ & $0.7 \pm 0.3$ \\
\hline & LOO (g/L) & $2.2 \pm 1.1$ & $2.3 \pm 1.1$ & $2.4 \pm 1.2$ & $2.8 \pm 0.8$ & $2.8 \pm 1.2$ & $2.5 \pm 0.9$ \\
\hline
\end{tabular}

$L O D$, detection limit; $L O Q$, quantification limit; $(\bar{x} \pm s)$, average \pm standard deviation. 
reported in the literature for HPAEC-PAD (LOD $<0.6 \mu \mathrm{g} / \mathrm{mL}$ and $\mathrm{LOQ}<2 \mu \mathrm{g} / \mathrm{mL})(34,36)$ and HPAEC-PED $(\mathrm{LOD}<12.5 \mu \mathrm{g} / \mathrm{mL}$ and $\mathrm{LOQ}<32 \mu \mathrm{g} / \mathrm{mL}$ ) (35).

\section{HPLC INSTRUMENTAL PRECISION, ACCURACY, AND RECOVERY ASSAYS}

The instrumental precision and accuracy of the proposed HPLCRI method were evaluated by analyzing 3 QCS with known concentrations of each sugar. The results obtained are shown in Table 6 . Based on the results obtained, it can be stated that the HPLC-RI method has an acceptable precision (\%RSD lower than 5\%) and a global satisfactory accuracy (\%RE lower, in general, than 6\%) $(40,41)$. In Table 7, the results concerning recovery evaluation are given showing that in general, recoveries between 80 and 120\% are obtained, which are in accordance with the values reported by Borromei et al. (43) regarding the application of a HPAEC-PAD method for prebiotics quantifications in fermented milk samples. Furthermore, the recoveries achieved with the present method are quite satisfactory since values between 50 and $120 \%$ are acceptable if the respective \%RSD is lower than $15 \%$ (44), which is the case $(\% \mathrm{RSD}<5 \%)$.

\section{DETECTION AND QUANTIFICATION OF FOS DURING FERMENTATION PROCESS}

Depending on the source and extraction/production conditions, different amounts and composition of an oligomer mixture can be obtained. Campbell et al. (20) observed that, in general, fruits have highest amount of 1-kestose, followed by $1^{\mathrm{F}}$-fructofuranosylnystose and nystose and vegetables have highest amount of 1-kestose, followed by nystose and $1^{\mathrm{F}}$ fructofuranosylnystose. However, some vegetables like chinese chive, endive, and Jerusalem artichoke have highest amounts of $1^{\mathrm{F}}$-fructofuranosylnystose followed by nystose and kestose. Therefore, FOS commercial preparations from plants can have different amounts of individual FOS and/or contain also sub-products as glucose, fructose, sucrose, or others fermentable sugars, thus being difficult to establish the prebiotic features of these products. Also, FOS biological activity is related to their molecular structure (27). Indeed, some studies reported that nystose can exhibit higher biological activity than 1-kestose $(28,29)$. Hence, it is crucial to optimize not only the FOS yield, but also the content of each individual oligomer, in order to obtain a product with higher market value. In this context, the aim of this work was to study FOS production, via sucrose fermentation, using A. aculea$t u s$, in order to obtain a product not only with a high amount of FOS but also with a known profile of individual oligomers. This imposes the use of time-consuming and expensive analytical techniques to monitor fermentation processes. Therefore, the in-house validated HPLC-RI method was applied to follow and monitor FOS production (Figure 2) during 3 independent fermentations. The methodology developed allowed quantifying 1-kestose, nystose, and $^{\mathrm{F}}$-fructofuranosylnystose and also the byproducts glucose and fructose, as well as the remaining amount of sucrose (Figure 3). Figure 2 illustrates the average FOS yield profile (g FOS/g initial sucrose) along time, and reveals a satisfactory reproducibility of the fermentation process. The production of FOS was influenced by the time of fermentation and a maximum
Table 6 | Precision and accuracy of the HPLC-RI analysis

\begin{tabular}{|c|c|c|c|c|}
\hline Compound & $\begin{array}{l}\text { QCS1 } \\
\text { (g/L) }\end{array}$ & $\begin{array}{l}\text { Average } \\
\text { concentration } \\
(\bar{x} \pm s, g / L)\end{array}$ & $\%$ RSD & $\%$ RE \\
\hline Fructose & 0.723 & $0.74 \pm 0.05$ & 7.10 & 2.35 \\
\hline Glucose & 0.719 & $0.76 \pm 0.03$ & 3.94 & 6.15 \\
\hline Sucrose & 0.719 & $0.76 \pm 0.03$ & 4.11 & 6.33 \\
\hline 1-Kestose & 0.714 & $0.76 \pm 0.04$ & 4.94 & 6.08 \\
\hline Nystose & 0.719 & $0.75 \pm 0.04$ & 5.95 & 4.80 \\
\hline $1^{\mathrm{F}}$-Fructofuranosylnystose & 0.714 & $0.74 \pm 0.01$ & 1.96 & 4.26 \\
\hline Compound & $\begin{array}{l}\text { QCS2 } \\
\text { (g/L) }\end{array}$ & $\begin{array}{l}\text { Average } \\
\text { concentration } \\
(\bar{x} \pm s, g / L)\end{array}$ & $\%$ RSD & $\%$ RE \\
\hline Fructose & 11.01 & $10.8 \pm 0.4$ & 4.01 & 1.79 \\
\hline Glucose & 10.94 & $10.8 \pm 0.4$ & 3.75 & 1.42 \\
\hline Sucrose & 10.95 & $10.7 \pm 0.2$ & 2.22 & 1.91 \\
\hline 1-Kestose & 10.87 & $10.6 \pm 0.2$ & 1.83 & 2.58 \\
\hline Nystose & 10.95 & $10.8 \pm 0.2$ & 1.77 & 1.54 \\
\hline $1^{\mathrm{F}}$-Fructofuranosylnystose & 10.87 & $10.6 \pm 0.1$ & 1.22 & 2.37 \\
\hline Compound & $\begin{array}{l}\text { QCS3 } \\
\text { (g/L) }\end{array}$ & $\begin{array}{l}\text { Average } \\
\text { concentration } \\
(\bar{x} \pm s, g / L)\end{array}$ & $\%$ RSD & $\%$ RE \\
\hline Fructose & 20.26 & $20.0 \pm 0.9$ & 4.41 & 1.13 \\
\hline Glucose & 20.13 & $20.0 \pm 0.9$ & 4.38 & 0.52 \\
\hline Sucrose & 20.14 & $20.2 \pm 0.3$ & 1.73 & 0.05 \\
\hline 1-Kestose & 20.00 & $19.8 \pm 0.3$ & 1.56 & 0.88 \\
\hline Nystose & 20.14 & $20.1 \pm 0.2$ & 1.24 & 0.41 \\
\hline $1^{\mathrm{F}}$-Fructofuranosylnystose & 20.00 & $19.7 \pm 0.3$ & 1.61 & 1.32 \\
\hline
\end{tabular}

$O C S$, quality control solution; \%RSD, relative standard deviation percentage; $\% R E$, relative error percentage; $(\bar{x} \pm s)$, average \pm standard deviation; Average concentration was calculated using the adequate linear calibration curve according to the concentration dynamic range; for QCS1 using data on Table 4; for QCS2 and QCS3 using data from Table 5.

Table 7 | Recovery assays.

\begin{tabular}{lccc}
\hline Compound & \multicolumn{3}{c}{ Average recoveries $(\overline{\boldsymbol{x}} \pm \mathbf{s}, \mathbf{\%})$} \\
\cline { 2 - 4 } & $\mathbf{2 5 \boldsymbol { \mu }}$ & $\mathbf{5 0} \boldsymbol{\mu \mathbf { L }}$ & $\mathbf{1 0 0} \boldsymbol{\mu \mathbf { L }}$ \\
& $\mathbf{( \approx \mathbf { 0 . 6 2 5 } \mathbf { ~ m g } )}$ & $\mathbf{( \approx \mathbf { 1 . 2 5 } \mathbf { ~ m } )}$ & $\mathbf{( \approx \mathbf { 2 . 5 0 } \mathbf { ~ g } )}$ \\
\hline Fructose & $71 \pm 2$ & $91.1 \pm 0.2$ & $94 \pm 4$ \\
Glucose & $92 \pm 1$ & $101 \pm 1$ & $104.0 \pm 0.1$ \\
Sucrose & $92.2 \pm 0.1$ & $103 \pm 1$ & $97.8 \pm 0.6$ \\
1-Kestose & $82.4 \pm 0.9$ & $94 \pm 3$ & $95 \pm 2$ \\
Nystose & $89 \pm 1$ & $98 \pm 2$ & $99 \pm 2$ \\
1F-Fructofuranosylnystose & $100.9 \pm 0.2$ & $121 \pm 2$ & $130 \pm 1$ \\
\hline
\end{tabular}

$(\bar{x} \pm s)$, average \pm standard deviation.

yield was obtained after $60 \mathrm{~h}$ of inoculation. Afterward, it was observed that the sucrose level remained almost constant, indicating that, after this moment, fungi had an apparently preference 


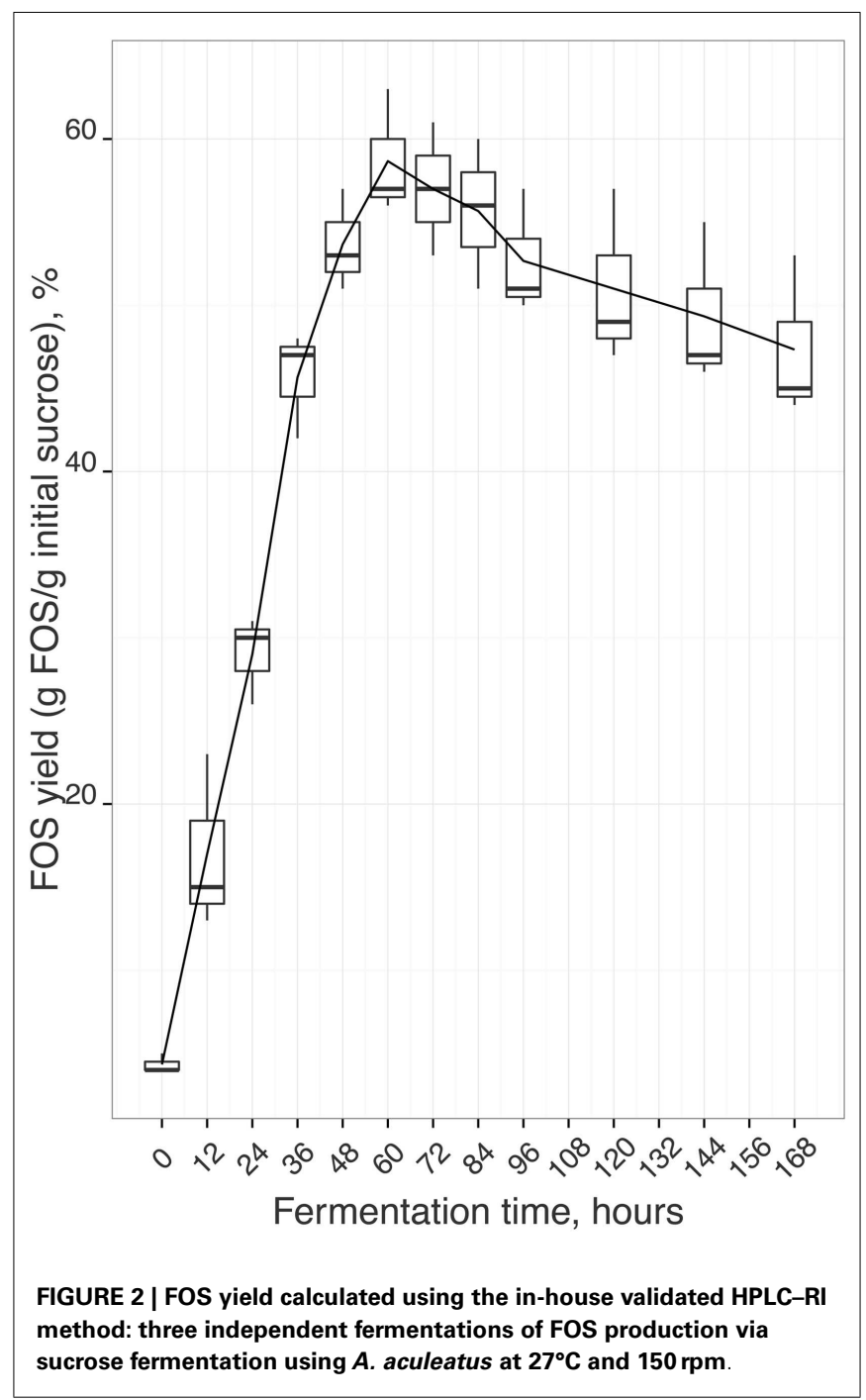

for consuming 1-kestose, thus influencing the oligomers relative ratios. As can be seen from Figure 3, when the maximum FOS yield was reached, the $1^{\mathrm{F}}$-fructofuranosylnystose was present in residual amounts, and 1-kestose was the most abundant oligomer. During the following $24 \mathrm{~h}$ of fermentation, the total FOS amount decreases, being observed a significant change of the individual FOS profiles, with a decrease of 1-kestose content, an increase of nystose concentration reaching its maximum value, and an almost constant level of $1^{\mathrm{F}}$-fructofuranosylnystose. After $84 \mathrm{~h}$ of fermentation, the yield of total FOS continues to decrease (Figure 2), the amount of nystose, and $1^{\mathrm{F}}$-fructofuranosylnystose remains practically constant and 1-kestose continues to be degraded with the concomitantly increase of the sub-product glucose. Therefore, the fermentation period between 60 and $84 \mathrm{~h}$ appears to be crucial for obtaining a final product with different ratios of 1-kestose and nystose, near to their maximum levels. The in-house validated HPLC-RI method revealed to be a simple and cost-effective methodology enabling to monitor individual FOS production and their eventual consumption during a fermentation process. In fact,

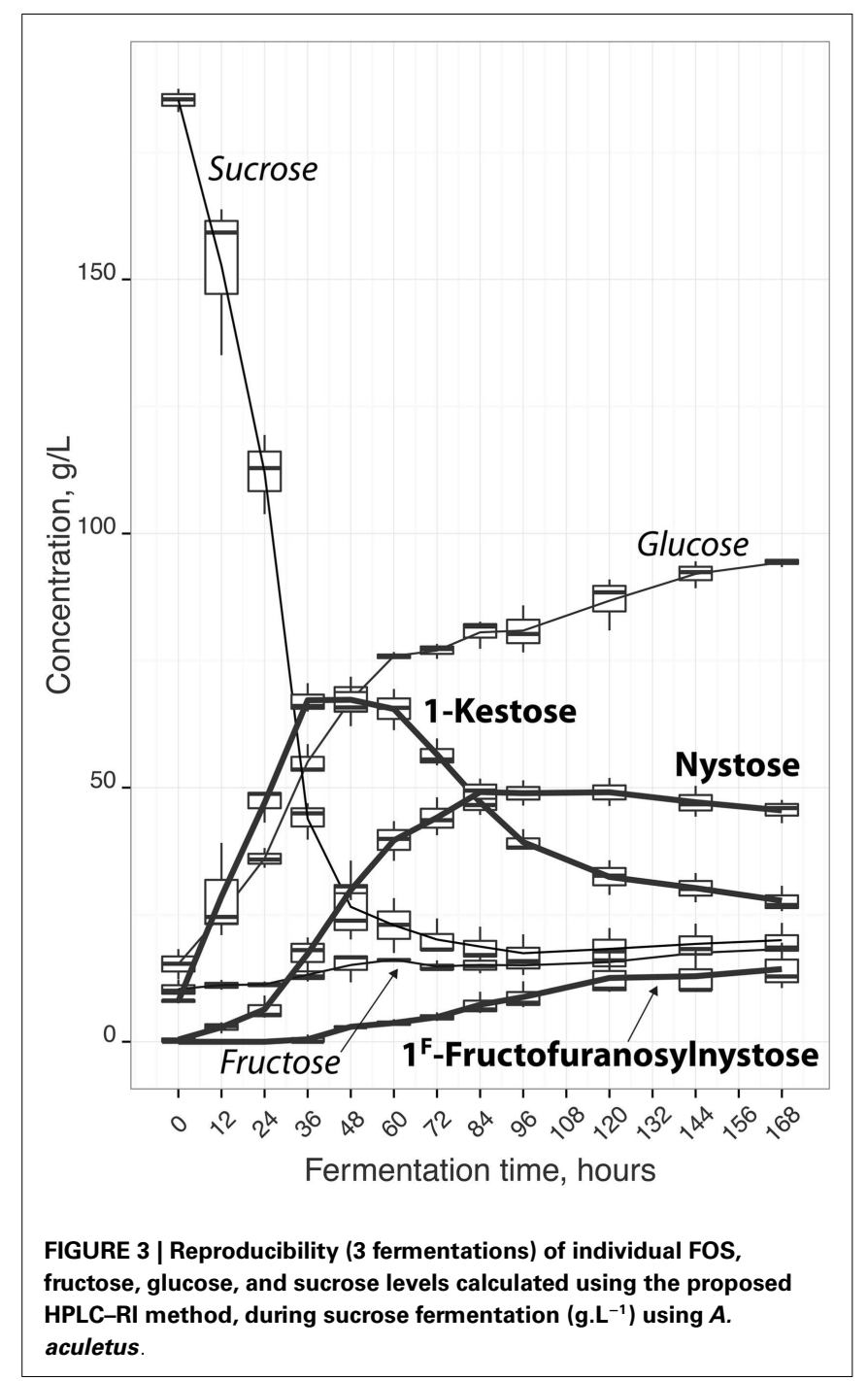

this analytical methodology allows the simultaneous identification of the optimal fermentation time for maximizing total or a specific individual FOS yield. So, it may allow identifying the optimal fermentation end-point, which maximizes the production of a specific oligomer, toward obtaining a final prebiotic product with a relative composition that may enhance biological activity and to improve the expected beneficial physiological effects. Finally, at industrial level, this method can be of surplus value for achieving a reproducible and homogeneous product in the minimum fermentation time. Despite the very satisfactory results obtained, as well as the potential of the proposed HPLC method for evaluating FOS production profiles during fermentation, it should be kept in mind that this methodology was specifically developed for fermentation matrices with a high content of FOS, and that the type of FOS present in these matrices were known beforehand. Thus, its application for matrices containing low amounts of FOS, such as plants and fruits extracts, may not be straightforward namely if the type of FOS in the matrices is unknown and/or no available standards exist. 


\section{CONCLUSION}

Fructooligosaccharides have a broad application in food, pharmaceutical, and veterinary studies, being increasingly important in food and nutrition sciences. Usually, FOS are produced by the action of enzymes possessing transfructosylating activity, which can be found both in plants and microorganisms. As such, the industrial production of FOS is highly dependent on enzymatic processes, being usually obtained through the sucrose fermentation by several fungi. Therefore, it is of major relevance to develop feasible analytical techniques that allow a fast and lowcost quantification of total and individual FOS. Their correct quantification may even allow a more precise nutritional formulation of new functional foods, since different FOS can exhibit different biological activities and effects. In this study, we demonstrated that a simple HPLC-RI method could be accurately used for the simultaneous quantification of 1-kestose, nystose, $1^{\mathrm{F}_{-}}$ fructofuranosylnystose, glucose, fructose, and sucrose present in samples collected during the FOS fermentative production from sucrose using $A$. aculeatus. The chromatographic method was validated in-house, showing a satisfactory intra- and inter-day variability (in general, $\% \mathrm{RSD} \leq 5 \%$ ), high sensitivity for each sugar (usually, $\% \mathrm{RE} \leq 5 \%)$, and low detection $(\leq 0.06 \pm 0.04 \mathrm{~g} / \mathrm{L})$ and quantification $(\leq 0.2 \pm 0.1 \mathrm{~g} / \mathrm{L})$ limits. Moreover, the proposed approach was fast (less than $30 \mathrm{~min}$ per run), cost-effective, and did not require any complex pre-treatment step. Furthermore, the proposed chromatographic based technique may be easily extended for the quantification of total or individual FOS in rich-FOS plant concentrated extracts or in food supplements, for which it is required to include FOS contents in label information. Nevertheless, the proposed method presents a limitation regarding full characterization of the fermentative product composition or its possible application to low FOS content matrices, which would require the complementary use of mass spectroscopy methods.

\section{ACKNOWLEDGMENTS}

This work was partially co-financed by FCT and FEDER under Program COMPETE (Project PEst-C/EQB/LA0020/2013), by the Strategic Project PEst-OE/EQB/LA0023/2013 and by the project ref. RECI/BBB-EBI/0179/2012 (project number FCOMP01-0124-FEDER-027462) funded by Fundação para a Ciência e a Tecnologia.

\section{REFERENCES}

1. Brokl M, Hernández-Hernández O, Soria AC, Sanz ML. Evaluation of different operation modes of high performance liquid chromatography for the analysis of complex mixtures of neutral oligosaccharides. J Chromatogr A (2011) 1218:7697-703. doi:10.1016/j.chroma.2011.05.015

2. Veloso ACA, Rodrigues LR, Dias LG, Peres AM. Chapter 14. UV spectrophotometry method for dietary sugars. In: Preedy VR, editor. Dietary Sugars Chemistry, Analysis, Function and Effects. Cambridge: The Royal Society of Chemistry Publishing (2012). p. 229-48. doi:10.1039/9781849734929-00229

3. Dominguez AL, Rodrigues LR, Lima N, Teixeira JA. An overview of the recent developments on fructooligosaccharide production and applications. Food Bioprocess Technol (2014) 7:324-37. doi:10.1007/s11947-013-1221-6

4. Sharp R, Fishbain S, Macfarlane GT. Effect of short-chain carbohydrates on human intestinal bifidobacteria and Escherichia coli in vitro. J Med Microbiol (2001) 50:152-60.

5. Knol J, Boehm G, Lidestri M, Negretti F, Jelinek J, Agosti M, et al. Increase of faecal bifidobacteria due to dietary oligosaccharides induces a reduction of clinically relevant pathogen germs in the faeces of formula-fed preterm infants. Acta Paediatr (2005) 94:31-3. doi:10.1080/08035320510043529

6. Chen L-W, Wu Y-Y, Chung P-H, Hsu C-M. Microbiota enhances intestinal immunity through JNK/ROS pathways. J Immunol (2014) 192:133.14.

7. Hartemink R, Van Laere KMJ, Rambouts FM. Growth of enterobacteria on fruto-oligosacharides. J Appl Microbiol (1997) 83:367-74. doi:10.1046/j.13652672.1997.00239.x

8. Sakai K, Aramaki K, Takasaki M, Inaba H, Tokunaga T, Ohta A. Effect of dietary short-chain fructooligosaccharides on the cecal microflora in gastrectomized rats. Biosci Biotechnol Biochem (2001) 65:264-9. doi:10.1271/bbb.65.264

9. Bovee-Oudenhoven IMJ, ten Bruggencate SJM, Lettink-Wissink MLG, van der Meer R. Dietary fructo-oligosaccharides and lactulose inhibit intestinal colonisation but stimulate trans-location of Salmonella in rats. Gut (2003) 52:1572-8. doi:10.1136/gut.52.11.1572

10. Petersen A, Heegaard PM, Pedersen AL, Andersen JB, Sorensen RB, Frokiaer $\mathrm{H}$, et al. Some putative prebiotics increase the severity of Salmonella enterica serovar Typhimurium infection in mice. BMC Microbiol (2009) 9:245. doi:10.1186/1471-2180-9-245

11. Silva DF, Mezêncio JMS, Vanetti MCD, Cecon PR, Santos ML. Translocation of Klebsiella sp. in mice fed an enteral diet containing prebiotics. Rev Nutr (2009) 22:229-35. doi:10.1590/S1415-52732009000200005

12. Schouler C, Taki A, Chouikha I, Moulin-Schouleur M, Gilot P. A Genomic Island of an extraintestinal pathogenic Escherichia coli strain enables the metabolism of fructooligosaccharides, which improves intestinal colonization. J Bacteriol (2009) 191:388-93. doi:10.1128/JB.01052-08

13. L'homme C, Peschet JL, Puigserver A, Biagini A. Evaluation of fructans in various fresh and stewed fruits by high-performance anion-exchange chromatography with pulsed amperometric detection. J Chromatogr A (2001) 920:291-7. doi:10.1016/S0021-9673(00)01262-0

14. Kretser AJ. The new Dietary Reference Intakes in food labelling: the food industry's perspective. Am J Clin Nutr (2006) 83:1231S-4S.

15. Blanch M, Sanchez-Ballesta MT, Escribano MI, Merodio C. Fructooligosaccharides in table grapes and response to storage. Food Chem (2011) 129:724-30. doi:10.1016/j.foodchem.2011.05.011

16. Dominguez A, Nobre C, Rodrigues LR, Peres AM, Torres D, Rocha I, et al. New improved method for fructooligosaccharides production by Aureobasidium pullulans. Carbohydr Polym (2012) 89:1174-9. doi:10.1016/j.carbpol.2012.03.091

17. Playne MJ, Crittenden RG. Prebiotics from lactose, sucrose, starch, and plant polysaccharides. In: Neeser J-R, German JB, editors. Bioprocesses and Biotechnology for Functional Foods and Nutraceuticals. New York: Marcel Dekker (2004). p. 88-117. doi:10.1201/9780203026380.ch7.

18. Roberfroid MB. Prebiotics: the concept revisited. J Nutr (2007) 137: 830S-7S.

19. Benkeblia N. Fructooligosaccharides and fructans analysis in plants and food crops. J Chromatogr A (2013) 1313:54-61. doi:10.1016/j.chroma.2013.08.013

20. Campbell JM, Bauer LL, Fahey GC Jr, Hogarth AJCL, Wolf BW, Hunter DE. Selected Fructooligosaccharide (1-Kestose, Nystose, and $1^{\mathrm{F}}-\beta$ Fructofuranosylnystose) composition of foods and feeds. J Agric Food Chem (1997) 45:3076-82. doi:10.1021/jf970087g

21. Blanch M, Sanchez-Ballesta MT, Escribano MI, Merodio C. Characterisation and functionality of fructo-oligosaccharides affecting water status of strawberry fruit (Fragraria vesca cv. Mara de Bois) during postharvest storage. Food Chem (2012) 134:912-9. doi:10.1016/j.foodchem.2012.02.203

22. Sangeetha PT, Ramesh MN, Prapulla SG. Recent trends in the microbial production, analysis and application of Fructooligosaccharides. Trends Food Sci Technol (2005) 16:442-57. doi:10.1016/j.tifs.2005.05.003

23. Kuhn RC, Maugeri Filho F. Separation of fructooligosaccharides using zeolite fixed bed columns. J Chromatogr B (2010) 878:2023-8. doi:10.1016/j.jchromb. 2010.05.039

24. Ganaie MA, Gupta US, Kango N. Screening of biocatalysts for transformation of sucrose to fructooligosaccharides. J Mol Catal B Enzym (2013) 97:12-7. doi:10.1016/j.molcatb.2013.07.008

25. Ganaie MA, Rawat HK, Wani OA, Gupta US, Kango N. Immobilization of fructosyltransferase by chitosan and alginate for efficient production of fructooligosaccharides. Process Biochem (2014) 49:840-4. doi:10.1016/j.procbio.2014.01.026

26. Tian F, Karboune S, Hil A. Synthesis of fructooligosaccharides and oligolevans by the combined use of levansucrase and endo-inulinase in one-step bi-enzymatic system. Innov Food Sci Emerg Technol (2014) 22:230-8. doi:10.1016/j.ifset.2013. 12.004 
27. Fabrik I, Cmelík R, Bobál’ová J. Analysis of free oligosaccharides by negativeion electrospray ion trap tandem mass spectrometry in the presence of $\mathrm{H}_{2} \mathrm{PO}^{4-}$ anions. Int J Mass Spectrom (2012) 309:88-96. doi:10.1016/j.ijms.2011.09.002

28. Zdunczyk Z, Król B, Juskiewicz J, Wróblewska M. Biological properties of fructooligosaccharides with different contents of kestose and nystose in rats. Arch Anim Nutr (2005) 59:247-56. doi:10.1080/17450390500216944

29. Pejin B, Savic AG, Petkovic M, Radotic K, Mojovic M. In vitro anti-hydroxyl radical activity of the fructooligosaccharides 1-kestose and nystose using spectroscopic and computational approaches. Int J Food Sci Technol (2013) 49:1500-5. doi:10.1111/ijfs.12445

30. Benkeblia N, Onodera S, Shiomi N. Effect of gamma irradiation and temperature on fructans (fructo-oligosaccharides) of stored onion bulbs Allium cepa L. Food Chem (2004) 87:377-82. doi:10.1016/j.foodchem.2003.12.010

31. Reiffová K, Nemcová R. Thin-layer chromatography analysis of fructooligosaccharides in biological samples. JChromatogr A (2006) 1110:214-21. doi:10.1016/ j.chroma.2006.01.039

32. Vågen IM, Slimestad R. Amount of characteristic compounds in 15 cultivars of onion (Allium cepa L.) in controlled field trials. J Sci Food Agric (2008) 88:404-11. doi:10.1002/jsfa.3100

33. Downes K, Terry LA. A new acetonitrile-free mobile phase method for LCELSD quantification of fructooligosaccharides in onion (Allium cepa L.). Talanta (2010) 82:118-24. doi:10.1016/j.talanta.2010.04.003

34. Borromei C, Cavazza A, Merusi C, Corradini C. Characterization and quantitation of short-chain fructooligosaccharides and inulooligosaccharides in fermented milks by high-performance anion-exchange chromatography with pulsed amperometric detection. J Sep Sci (2009) 32:3635-42. doi:10.1002/jssc. 200900322

35. Borromei C, Careri M, Cavazza A, Corradini C, Elviri L, Mangia A, et al. Evaluation of Fructooligosaccharides and inulins as potentially health benefiting food ingredients by HPAEC-PED and MALDI-TOF MS. Int J Anal Chem (2009) 2009:9. doi:10.1155/2009/530639

36. Feinberg M, San-Redon J, Assié A. Determination of complex polysaccharides by HPAE-PAD in foods: validation using accuracy profile. J Chromatogr B (2009) 877:2388-95. doi:10.1016/j.jchromb.2008.10.004

37. Lorenzoni AS, Aydos LF, Klein MP, Rodrigues RC, Hertz PF. Fructooligosaccharides synthesis by highly stable immobilized $\beta$-fructofuranosidase from Aspergillus aculeatus. Carbohydr Polym (2014) 103:193-7. doi:10.1016/j.carbpol. 2013.12.038
38. Onofrejová L, Farková M, Preisler J. Quantification of fructo-oligosaccharides based on the evaluation of oligomer ratios using an artificial neural network. Anal Chim Acta (2009) 638:191-7. doi:10.1016/j.aca.2009.02.034

39. Nagai A, Yamamoto T, Wariishi H. identification of fructo- and maltooligosaccharides in cured tobacco leaves (Nicotiana tabacum). JAgric Food Chem (2012) 60:6606-12. doi:10.1021/jf301395v

40. Ermer J, Miller JHMcB, editors. Method Validation in Pharmaceutical Analysis. A Guide to Best Practice. Weinheim: Wiley-VCH Verlag GmbH \& Co (2005).

41. Snyder LR, Kirkland JJ, Dolan JW. Introduction to Modern Liquid Chromatography. 3rd ed. New Jersey: John Wiley \& Sons Inc (2010).

42. Dominguez A, Santos IM, Teixeira JA, Lima N. New and simple test plating for screening relative transfructosylation activity of fungi. Rev Iberoam Micol (2006) 23:189-91. doi:10.1016/S1130-1406(06)70042-0

43. Borromei C, Cavazza A, Corradini C, Vatteroni C, Bazzini A, Ferrari R, et al. Validated HPAEC-PAD method for prebiotics determination in symbiotic fermented milks during shelf life. Anal Bioanal Chem (2010) 397:127-35. doi:10.1007/s00216-010-3510-5

44. Ribani M, Bottoli CBG, Collins CH, Jardim I, Melo LFC. Validation for chromatographic and electrophoretic methods. Quim Nova (2004) 27:771-80. doi:10.1590/S0100-40422004000500017

Conflict of Interest Statement: The authors declare that the research was conducted in the absence of any commercial or financial relationships that could be construed as a potential conflict of interest.

Received: 27 May 2014; paper pending published: 09 June 2014; accepted: 16 July 2014; published online: 31 July 2014.

Citation: Correia DM, Dias LG, Veloso ACA, Dias T, Rocha I, Rodrigues LR and Peres AM (2014) Dietary sugars analysis: quantification of fructooligossacharides during fermentation by HPLC-RI method. Front. Nutr. 1:11. doi: 10.3389/fnut.2014.00011 This article was submitted to Nutrition and Food Science Technology, a section of the journal Frontiers in Nutrition.

Copyright (c) 2014 Correia, Dias, Veloso, Dias, Rocha, Rodrigues and Peres. This is an open-access article distributed under the terms of the Creative Commons Attribution License (CC BY). The use, distribution or reproduction in other forums is permitted, provided the original author(s) or licensor are credited and that the original publication in this journal is cited, in accordance with accepted academic practice. No use, distribution or reproduction is permitted which does not comply with these terms. 